\title{
Creative Writing, Behaviour, and Behavioral Psychology: Descriptive Study in the Indonesian Language and Literature Department
}

\author{
Anas Ahmadi \\ Universitas Negeri Surabaya \\ Surabaya, Indonesia \\ anasahmadi@unesa.ac.id
}

\author{
Setya Yuwana Sudikan \\ Universitas Negeri Surabaya \\ Surabaya, Indonesia \\ setyayuwana@unesa.ac.id
}

\author{
Budinuryata Yohanes \\ Universitas Negeri Surabaya \\ Surabaya, Indonesia \\ budinuryanta@unesa.ac.id
}

\begin{abstract}
The purpose of this research is to explore the student behavior in creative writing using behavioral psychology prospective. The research are using qualitative approach that been strengthen with narrative texts. The subject of the research is the 36 students from language and literature of Indonesia. Data analysis technique is used by identification, classification and data display that related with the act of writing that connected with behavioral psychology perspective. The data technique is collected through interview, discussion and survey. The results of the research shows that there is a changing behavior of student in writing. The students are preferred to follow an exposure by the researcher rather than writing own themselves. Other than that, psychologically the students are more likely like to get stimulus in creative writing.
\end{abstract}

Keywords-Creative Writing; literature; behavior; behavioral psychology.

\section{INTRODUCTION}

Writing and psychology are two field of study that has similarity which is both of them involved an idea or mental process [9]; [18]; [2]. Study of psychology is indeed gone to the other side of science discipline. This matters shows that a study of interdisciplinary are interesting for many researcher since it is able to answer the challenge of complex knowledge [1]; [16].

Writing is a material that has a high complexity in language skill. That is why, it is needed a new breakthrough in writing learning. The new breakthrough of writing could also related to its strategy [15] and its purpose whether in context of monodisciplinary studies, interdisciplinary study or transdisciplinary [13]; [14]. Through the breakthrough, it is hoped that writing could become something that is not considered as a hard material.
Relating to the fact of writing, on this article purposed is to show the writing behavior that is related with psychological context. On this matters, the writing behavior are being connected with behavioral psychology. Behavioral psychology is a psychology that put forward behavior as their core. Because of that, this psychology focused on the effect of changes and stimulus that been created by the environment as the study medium [4]; [8]; [17]. This psychology is well known as a theory of stimulus respond and in the modern era it is well known by the academician who are focused in environment.

Behavioral psychology is used in the contexts of education especially in a connection of study toward behavior changes, behavior increase, decrease of interest, or even the increase of interest in study [19]; [6]; [20]. Through the behavioral psychology, a researcher of educative contexts could observe the behavior changes that shown by the subject of research. This behavior change could also related with positive respond or negative respond. In psychology behavioral context, respond from the subject could appeared positively or negatively. Depending on the stimulus that been given by the researcher when giving a treatment [10]. In this context, researchers also do not fully use behavioral psychology, but are also supported by cognitive behavioral therapy (CBT). Through this CBT, a person can get therapy, treatment, and handling a problem positively in the hope that it can produce positive things as well [12]; [11]; [3].

\section{METHODS}

This research used the qualitative approach because it will display more data in narrative, empirical, and interpretive [5]; [7]. The subject of the research is the student of language and literature of Indonesia, State University of Surabaya (UNESA) with a total 36 students. The technique of collecting the data 
was done with (1) Interview, (2) Survey, (3) Writing practice (context of creative writing [Literature]). The technique of analyzing the data covered the step of pre-writing, writing, and post-writing. This is due to strengthen and validate the results of the research, which is done a data triangulation, triangulation theory, and triangulation of methodology. Those triangulation were done simultaneously for the results to be more comprehensive.

\section{RESULTS AND DISCUSSION}

In the relation for understanding the writing behavior in the student using behavioral psychology consisted of three steps done by the researcher. Those three steps are done step by step with categories of three meeting.

First, the interview and the survey fulfillment relating to the difficulty of creative writing. From 36 students of language and literature of Indonesia they are very enthusiast in creative writing. This matters appeared during the interview and open discussion with the students. They are very happy when learning creative writing, especially in short story. From the student respond in the interview, they are more like short story because of the depth level, concentration level and metaphor level does not deep like writing poetry. However, there is 20 percent of student who has difficulties in creative writing. The difficulties of creative writing on the student has divided into eight primary which it (1) Difficulties in concentration for creative writing, (2). Difficulties of creative writing because they feel unconfident in writing, (3) Unable to imaginary writing because of the likeness of writing fact, (4) does not have a good idea, (5) Difficulties in structuring the story, (6) does not interested in fiction, (7) Having difficulties of finding an idea/inspiration, (8) does not have a friend for discussion.

Firstly, the action that are given to the student through behavioral psychology. When, the root of problem that is connected with the difficulties of creative writing already found, the researcher gives an action to them. Those action covered two things. Firstly, motivation given to the students through suggestion, briefing, and affirming. The concretization of the suggestion, direction, and affirmation related to the difficulty of the student when he has difficulty writing is to provide input so that he participates in (i) activities related to writing seminars or writing workshops so that he gets input on writing; ii) take part in the writing community on campus or outside campus. That way, students can get individual experience related to writing in the community; (iii) providing input, direction, and affirmation so that students not only learn self-taught, but they need teachers who are experts in writing; and (iv) if there are students who really find it difficult to write, he can be directed to a psychologist to identify problems that cause him difficulty in writing.
Secondly, the student are given a task to write a creative writing. Through the given action which being continued with task distribution was hoped for the student to change their behavior in writing. The task in writing short story are based on the theme they like. However, the researcher are still given a criteria for the creative writing (in this matter short story) for them to stay on the right path of writing. The criteria of writing short story covered of originality, depth of diction, depth of theme, and the latest they offered to the reader.

Third, doing a discussion and interview as a form of reflection from the writing behavior. After the student finish writing, the student were invited to a discussion and interview in relation of the writing process. From this discussion and interview, it is collected as presented (1) the student prefer to write something that is popular, while writing in philosophy theme are rarely. This matter is caused by the age that contribute to the style of writing. (2) The student are preferred to followed the theme or title that been suggested by the researcher because it is considered as a best reference. Even they choose the theme that is picked by the researcher in hope they can get a good score.(3)The student are like to write with a spontaneous technique rather than incubation technique and (4) stimulus injection in writing are very good in order to increase the student motivation in writing.

\section{CONCLUSION}

Writing in the student circle does not only need a skill in pouring an idea, but as well it is needed a stimulus inducement that is connected with psychology. Which, the discipline of psychology science are needed in writing. Based on the discussion, it is concluded that the student are preferred the stimulus that is induced by the researcher rather than bring our new idea in writing. Other than that, writing that been given a stimulus in the psychology context are more fun and interesting in the student mind.

\section{REFERENCES}

[1] A. Ahmadi, A. S. Ghazali, T. Dermawan, Maryaeni. "Ecopsychology and Psychology of Literature:Concretization of Human Biophilia Tha Loves the Environment in Two Indonesian Novels," The International Journal of Literary Humanities, 7(1), pp. 47-59, 2019.

[2] B. Barron, "The Psychology Of The Creative Writer" Theory Into Practice, 5(4), pp. 157-159, 2009.

[3] B. L. Pearson, \& T. S. Cordiano, Can We Play Again?: Applying Positive Psychology Principles in Cognitive-Behavioral Play Therapy. In Happiness, Healing, Enhancement, G. W. Burns (Ed.). doi:10.1002/9781118269664.ch22, 2012.

[4] C. D. Reisener, D. L. Gadke, T. Ho, C. M. Jostad, "The Effects of Behavioral Skills Training on Teachers' Implementation of Guided Compliance," Journal of Psychology and Behavioral Science, 2(3\&4). DOI: 10.15640/jpbs.v2n3-4a1, 2014

[5] C. Sam, "Activity Theory and Qualitative Research in Digital Domains," Theory Into Practice, 51(2), pp. 8390, DOI: 10.1080/00405841.2012.662856, 2012.

[6] Camp H., "The psychology of writing development-And its implications for assessment," Assessing Writing, 17(2), pp. 92-105, 2012. 
[7] Creswell, J. W., Research Design: Qualitative \& Quantitative Approaches. Thousand Oaks, Calif: Sage Publications, 1994.

[8] D. E. M. Al-Kfaween, "Behavioral Motivation of Tafila Technical University Students," J. Psychol. Behav. Sci., vol. 5, no. 2, pp. 23742380. DOI: 10.15640/jpbs.v5n2a7, 2017.

[9] E. Thys, B. Sabbe, M. De Hert, "The Assessment Of Creativity In Creativity/Psychopathology Research - A Systematic Review," Cognitive Neuropsychiatry, 19(4), pp. 359-377, 2014.

[10] Hall C. S. \& Linzey G., Teori-teori Sifat dan Behavioristik, Kanisius: Yogyakarta, 1993

[11] I. Lopez-Gomez, C. Chaves, G. Hervas, C. Vazquez, "Comparing the acceptability of a positive psychology intervention versus a cognitive behavioural therapy for clinical depression," Clin. Psychol. Psychother., 24(5), pp. 1029-1039. Available at: https://doi.org/10.1002/cpp.2129, 2017.

[12] J. Somers, Cognitive Behavioural Psychology, Harbour Centre, Faculty of Health Sciences. Vancouver BC, 2007.

[13] Luo L., \& Kiewra K., "Soaring to Successful Synthesis Writing," Journal of Writing Research, 11(1), pp. 163-209. Available at: https://doi.org/10.17239/jowr-2019.11.01.06, 2019.

[14] M. MacRobert, "Right before Writing," Journal of Literary Studies, 26(2), pp. 33-43, 2010
[15] M. Silva A, \& Limongi R., "Writing to Learn Increases Long-term Memory Consolidation: A Mental-chronometry and Computationalmodeling Study of "Epistemic Writing"," Journal of Writing Research, 11(1), pp. 211-243. Available at: doi: 10.17239/jowr-2019.11.01.07, 2019.

[16] N. R. Hariyati \& A. Ahmadi, "Effectiveness Learning of Critical Reading Using Susiso Model," 2nd Workshop on Language, Literature, and Society for Education, Solo: EAI [cited 27 July 2019], pp. 423-428. Available from: https://eudl.eu/doi/10.4108/eai.21-12-2018.2282657, 2019

[17] P. M, A. G., "Exercise Addiction and Alexithymia," Journal of Psychology and Behavioral Science, 3(1). DOI: 10.15640/jpbs.v3n1a7, 2015.

[18] S. H. Carson, J. Fama, K. Clancy, J. Ebert, \& A. Tierney, Writing for Psychology. Harvard: President and Fellows of Harvard College, 2012.

[19] Schutte N, Malouff J., "Dimensions of Reading Motivation Development of an Adult Reading Motivation Scale," Reading Psychology, 28(5), pp. 469-489, 2007.

[20] Y. Wang, S. Gennari, "How language and event recall can shape memory for time," Cognitive Psychology, vol. 108, pp. 1-21. Available at: https://doi.org/10.1016/i.cogpsych.2018.10.003, 2019. 